\title{
All-Solid-State Screen-Printed Sensors for Potentiometric Calcium(II) Determinations in Environmental Samples
}

\author{
Johannes Schwarz ${ }^{1 *}$, Kathrin Trommer ${ }^{1}$, Frank Gerlach1, Michael Mertig ${ }^{1,2}$ \\ ${ }^{1}$ Kurt-Schwabe-Institut für Mess- und Sensortechnik e.V. Meinsberg, Waldheim, Germany \\ ${ }^{2}$ Institut für Physikalische Chemie, Technische Universität Dresden, Dresden, Germany \\ Email: *schwarz@ksi-meinsberg.de
}

How to cite this paper: Schwarz, J., Trommer, K., Gerlach, F. and Mertig, M. (2018) All-Solid-State Screen-Printed Sensors for Potentiometric Calcium(II) Determinations in Environmental Samples. American Journal of Analytical Chemistry, 9, 113-123.

https://doi.org/10.4236/ajac.2018.93010

Received: January 25, 2018

Accepted: March 6, 2018

Published: March 9, 2018

Copyright $\odot 2018$ by authors and Scientific Research Publishing Inc. This work is licensed under the Creative Commons Attribution-NonCommercial International License (CC BY-NC 4.0). http://creativecommons.org/licenses/by-nc/4.0/

\begin{abstract}
This paper describes preparation, characterization and electrochemical performance of novel planar miniaturized all-solid-state (ASS) screen-printed potentiometric sensors for the detection of $\mathrm{Ca}^{2+}$ ions in environmental samples. Screen-printed graphite-based ion-selective electrodes (ISEs) and screenprinted reference electrodes based on silver-containing pastes have been applied in a space saving manner on common ceramic substrates with small dimensions. Applications to environmental samples are shown by direct potentiometry and potentiometric titrations in real water samples. Conducting polymers (CPs) have been used as solid-contact materials and as intermediate layer between the polyvinyl chloride (PVC)-containing ion-selective membrane and the graphite-containing substrate. Different diamides have been incorporated into the PVC membrane. In the range from $10^{-4} \mathrm{~mol} / \mathrm{L}$ to $10^{-1}$ $\mathrm{mol} / \mathrm{L}$, the ISEs show linear slopes of $27 \mathrm{mV} /$ decade, which is close to the Nernstian response. Moreover, the ISEs have response times of $<25 \mathrm{~s}$ and a life time of $>6$ months. The novel potentiometric ASS sensors enable simple and exact $\mathrm{Ca}^{2+}$ determinations in real samples.
\end{abstract}

\section{Keywords}

All-Solid-State Sensor, $\mathrm{Ca}^{2+}$-Selective Electrode, Potentiometric Titration, Environmental Samples

\section{Introduction}

During the last years, there has been an increasing demand for chemical analyzers, which are suited for a rapid, accurate and in-field ion analysis. There is a 
great interest for easy to use, sensitive, low-cost and maintenance-free chemical analyzers for economical real-time analysis of environmentally important ions. Potentiometric sensors can fulfill these requirements and can be easily adjusted to continuous and automatic analysis. Solid-contact ISEs without internal solution are especially attractive and desirable for on-site and mobile ion monitoring. ISEs in ASS configuration are portable and easy to handle since they exhibit no risk of solution leakages due to their simple construction form. In particular, they are suitable and applicable for on-site measurements and field applications. These electrode types are more convenient for remote monitoring than conventionally liquid-filled ISEs as they are compatible with microfabrication techniques, and thus, are easier to miniaturize. Most of the described $\mathrm{Ca}^{2+}$-selective ISEs use PVC as the polymer membrane matrix with immobilized organic ioncomplexing compounds. Ionophores and membrane components must be synthesized with great effort. Internal electrolyte solutions and commercial reference Ag/ AgCl electrodes are often used [1] [2] [3] [4].

Analysis by solid-contact electrochemical sensors produced by screen-printed technology is in accordance with the general trend in modern chemical analysis towards the use of analytical devices that should be amenable to microfabrication and mass production. Screen-printing technology has been successfully applied to production of electronic circuits and mass production of disposable electrochemical sensors [5]-[17].

Screen-printing is a versatile technique for production of low-cost, disposable planar sensors in high numbers because of the simple and rapid production process. It can successfully be applied to electrochemical ASS sensors for environmental applications. Attractive advantage of this technology is the versatility to print different thick film inks easily and quickly on inexpensive substrates allowing flexible electrode layouts and configurations. Furthermore, it offers great variability in mixing sensitive specific modifiers to the base ink.

Conjugated CPs are gaining increasing importance as electrode materials, because they can replace and eliminate the internal electrolyte used in conventional ISEs. They act as ion-to-electron transducers due to their coupled ionic and electronic conductivity, and therefore, stabilize the potentiometric response due to their high capacitance and reversible charge transfer. CPs can be electrochemically deposited on conductor materials and easily coated with ion-selective PVC membranes [18] [19].

Usual routinely used instrumental laboratory analysis methods for $\mathrm{Ca}^{2+} \mathrm{de}$ terminations such as atom absorption spectrometry or ion chromatography require expensive equipment and qualified personal. They are often not suitable for field analysis. Potentiometric $\mathrm{Ca}^{2+}$ determination using screen-printed ASS sensors can be a promising and advantageous alternative with high precision and accuracy, compared to the routinely used photometric and chromatography methods.

Calcium is an essential nutrient. It plays an important role in many biological 
and biochemical processes. $\mathrm{Ca}^{2+}$ amount and water hardness are important indicators for water quality. Therefore, determination of $\mathrm{Ca}^{2+}$ ions in environmental samples is of great importance.

In this work we report on preparation and applications of novel solid contact screen-printed sensors for potentiometric $\mathrm{Ca}^{2+}$ detections. Applications in tap and surface water samples are demonstrated.

\section{Experimental}

\subsection{Reagents and Materials}

Reagent grade high molecular weight poly vinyl chloride (PVC), tetrahydrofuran, ethylenediaminetetraacetic acid disodium salt dihydrate ( $\mathrm{Na}_{2}$-EDTA), pyrrole, poly(3,4-ethylenedioxythiophene)-poly(styrene sulfonate) (PEDOT: PSS), calconcarboxylic acid, 2-nitrophenyl octyl ether (2-NPOE) and calcium sulfate $\left(\mathrm{CaSO}_{4}\right)$ were purchased from Sigma Aldrich and used without further purification. All inorganic salts used were purchased from Sigma Aldrich. All aqueous solutions were prepared with deionized water with a conductivity of 0.055 $\mu \mathrm{S} / \mathrm{cm}$. Graphite and silver containing thick film inks, used for the screenprinted electrodes, were obtained from DuPont de Nemours. Tap water samples for titration were adjusted to $\mathrm{pH} 12$ by adding $\mathrm{NaOH}(2 \mathrm{~mol} / \mathrm{L})$. Plasticizers and ion-complexing compounds were available of highest purity and used without further purification. The ionophores were used without further purification.

\subsection{Equipment}

A half-automatic screen printer (EKRA mat S30, EKRA Germany) has been used to manufacture screen-printed sensors. Potentiometric measurements were carried out at room temperature, using pH/Ion analyzers pMX 3000 (WTW, Germany) and LM 2000 (Sensortechnik Meinsberg, Germany) with software ACHAT and LM remote. An ion chromatography system (IC 850 Metrohm, Switzerland) has been used for reference analysis.

\section{Results and Discussion}

\subsection{Electrode Preparation}

Manufacture of the ISEs has been realized by screen-printing graphite on ceramic substrates with defined dimensions, followed by specific modification with functional polymeric layers.

In Figure 1 diamides which have been used as ion-complexing materials are shown. Both substances can be successfully used as $\mathrm{Ca}^{2+}$-complexing compounds in ASS ISEs.

The membrane components were dissolved in tetrahydrofuran (THF) and applied to the top of the conducting polymer layer by drop casting. Best results have been achieved using the membrane compositions shown in Table 1. The weight percentage of each compound is given in brackets. Further investigations on systematic and optimized membrane compositions are currently taken place. 


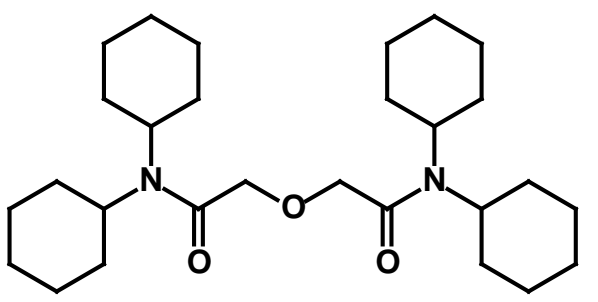

(a)

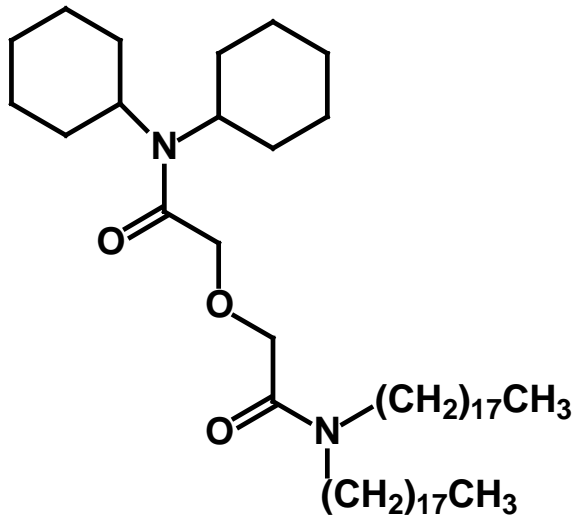

(b)

Figure 1. Chemical structure of the different $\mathrm{Ca}^{2+}$-complexing compounds: (a) $N, N, N$, $N$ 'tetra(cyclohexyl)diglycolic acid diamide; (b) $N, N$-dicyclohexyl- $N$ ', $N$ '-dioctadecyldiglycolic diamide.

Table 1. Membrane composition.

\begin{tabular}{cccc}
\hline Component & Membrane A [wt\%] & Membrane B [wt\%] & Membrane C [wt\%] \\
\hline ionophore & compound I [2.0\%] & compound I [1.0\%] & compound II [1.0\%] \\
& Poly(vinyl chloride) & Poly (vinyl chloride) & Poly(vinyl chloride) \\
polymer & high molecular weight & high molecular weight & high molecular weight \\
& {$[33.0 \%]$} & {$[32.8 \%]$} & {$[32.9 \%]$} \\
plasticizer & Bis(2-ethylhexyl)phthalate & 2-Nitrophenyl octyl ether & 2-Nitrophenyl octyl ether \\
& {$[64.0 \%]$} & {$[65.6 \%]$} & {$[65.8 \%]$} \\
additive & Potassium tetrakis & Potassium tetrakis & Potassium tetrakis \\
& (4-chlorophenyl)borate & (4-chlorophenyl)borate & (4-chlorophenyl)borate \\
& {$[1.0 \%]$} & {$[0.6 \%]$} & {$[0.3 \%]$}
\end{tabular}

In the first step graphite has been was screen printed on the ceramic substrates. Then the intermediate layer of $\mathrm{CP}$ was applied followed the ion selective membrane.

The graphite substrate is circular shaped with a diameter of $3 \mathrm{~mm}$. The dimension of the complete sensor is $30 \mathrm{~mm} \times 5 \mathrm{~mm}$. The transducer is covered by a conducting polymer (layer I) and by the ion-selective PVC membrane (layer II).

In this work, polypyrrole (PPy) and PEDOT:PSS have been used as intermediate layers between membrane and substrate. PPy is prepared by in-situ electrochemical oxidation with cyclovoltammetry on the screen-printed graphite in an aqueous solution of pyrrole and KCl. PEDOT:PSS solutions have been ap- 
plied onto the graphite transducer by drop casting. PPy and PEDOT:PSS have been used as solid-contact material and intermediate layer between the electronically conducting substrate and the ionically conducting ISE membrane. Both CPs adhere well on the graphite substrate.

Figure 2 shows the developed miniaturized potentiometric sensor with working and reference electrode (I) and the schematic construction form (II).

The reference electrodes were also manufactured by screen-printing technology and positioned together with the ISEs on a common ceramic substrate of definite dimensions.

First, a circular layer of $\mathrm{Ag}$ ink, and subsequently, a layer of a mixture of $\mathrm{Ag}$ and $\mathrm{AgCl}$ inks have been screen printed on the graphite transducer. These screen-printed ASS- $\mathrm{Ag} / \mathrm{AgCl}$ electrodes have been used without further modifications and enables stable potentials in the chloride containing measuring solutions. The reference electrodes are integrated in a space-saving way together with ISEs on a common ceramic based platform. The reference electrodes show stable potentials in electrolyte with constant chloride concentrations-also in the environmental samples. The thickness of both the screen-printed graphite and the $\mathrm{AgCl}$ layer is about $25 \mu \mathrm{m}$. The diameter of both the circular shaped planar graphite and the $\mathrm{AgCl}$ electrodes is $3 \mathrm{~mm}$. The reference electrodes are circular shaped, too. The distance between ion-selective electrode and reference electrode is $5 \mathrm{~mm}$.

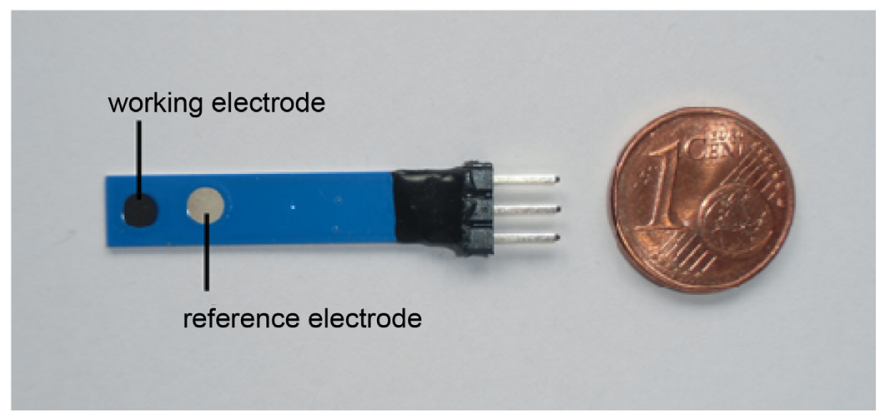

(a)

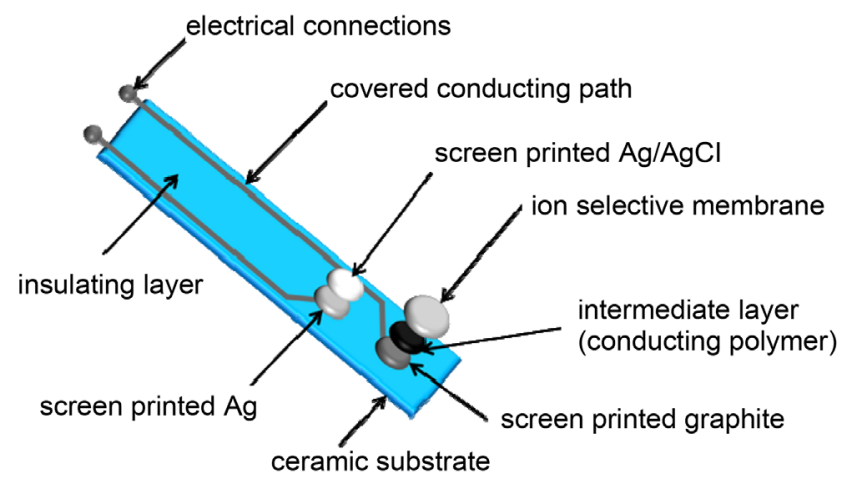

(b)

Figure 2. Photography (a) and schematic view (b) of a screenprinted potentiometric ASS sensor. 


\subsection{Potentiometric Investigations}

Potentiometric response behavior of a $\mathrm{Ca}^{2+}$-selective electrode in different standard solutions and in real samples (I) as well as a calibration plot (II) are shown in Figure 3. Compound I (Figure 2) was used as ionophore. The response time is lower than $20 \mathrm{~s}$. A constant $\mathrm{Cl}^{-}$concentration of $1 \mathrm{~mol} / \mathrm{L}$ has been used in the standard solutions for stabilizing the reference potential. The ASS sensor shows a stable potential in real samples. The $\mathrm{Ca}^{2+}$ amounts were determined by direct potentiometry in real samples: Sample 1 (well water) $80 \mathrm{mg} / \mathrm{L}$, sample 2 (tap water) $32 \mathrm{mg} / \mathrm{L}$, sample 3 (mineral water) $43 \mathrm{mg} / \mathrm{L}$. Comparative measurements by ion chromatography confirmed these results.

The slope is $>27 \mathrm{mV} /$ decade on average. Correlation coefficients of $>0.999$ were obtained.

The results confirm the good performance of these sensors for analysis in real water samples.

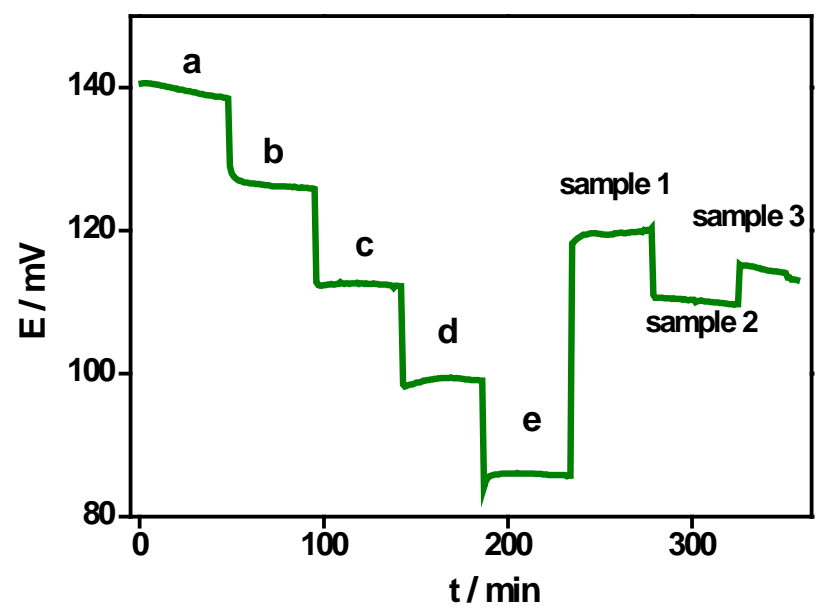

(a)

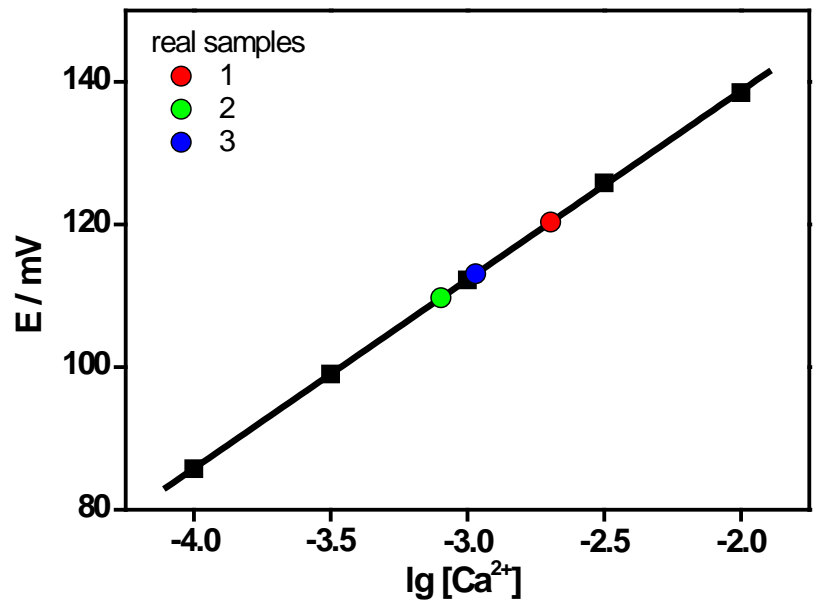

(b)

Figure 3. Response behaviour (a) and calibration plot (b) of a $\mathrm{Ca}^{2+}$-selective electrode; standards of $\mathrm{CaSO}_{4}$ : a. $10^{-2} \mathrm{~mol} / \mathrm{L}$, b. $10^{-2.5} \mathrm{~mol} / \mathrm{L}$, c. $10^{-3} \mathrm{~mol} / \mathrm{L}, \mathrm{d} .10^{-3.5} \mathrm{~mol} / \mathrm{L}$, e. $10^{-4}$ $\mathrm{mol} / \mathrm{L}$; sample 1: well water, sample 2: tapwater, sample 3: mineral water. 
Selectivity coefficents have been determined by applying the fixed interference method (FIM).

The constant concentration of the respective interfering ions was $10^{-2} \mathrm{~mol} / \mathrm{L}$. Following selectivity coefficents for the chosen interfering ions have been evaluated:

- $\lg K:-1.7$ (interfering ion: $\mathrm{Na}^{+}$),

- $\lg K:-1.9$ (interfering ion: $\mathrm{Mg}^{2+}$ ),

- $\lg K:-2.0$ (interfering ion: $\mathrm{Cu}^{2+}$ ).

\subsection{Applications}

Direct potentiometric $\mathrm{Ca}^{2+}$ determinations of different samples have been carried out with the newly developed sensors. In Table 2 determined $\mathrm{Ca}^{2+}$ concentrations in different real samples using the novel potentiometric ASS sensors and ion chromatography as reference method are shown. The obtained results confirm the good applicability and efficient operational capability of the novel ASS sensors for $\mathrm{Ca}^{2+}$ detection.

Titration as a calibration-free method is still an often used and accurate method for ion analysis. Focus of our work was to test the applicability of the novel sensors in potentiometric titration. Tap water samples from different European countries have been analyzed by potentiometric titration using the novel ASS sensors. $\mathrm{Ca}^{2+}$ concentrations have been evaluated and the results have been compared with standard complexometric titration, where no calibration is needed. Both ion-complexing substances are well suited for the indicator electrodes. The screen-printed ion-selective electrodes have been successfully used as indicator electrodes.

In Figure 4 potentiometric titration curves (a) including the first derivatives (b) of different tap water samples (I - IV) are shown. Potentials were registered against screen-printed ASS pseudo reference electrodes based on $\mathrm{AgCl}$ inks. There are significant potential jumps of $>100 \mathrm{mV}$ at the equivalent points. The sharp equivalent point allows a precise and accurate analytical $\mathrm{Ca}^{2+}$ determination. These results confirm the applicability and good performance of the novel screen-printed, solid-contact sensors. Tap water samples from European regions were analyzed, showing different $\mathrm{Ca}^{2+}$ contents. The determined $\mathrm{Ca}^{2+}$ concentrations are reliable indicators for water hardness. Thus, potentiometric titration using miniaturized potentiometric sensors offers a promising alternative determination method of high accuracy compared to colorimetric titration.

In Table 3 determined $\mathrm{Ca}^{2+}$ concentrations by potentiometric titrations of

Table 2. Determined $\mathrm{Ca}^{2+}$ concentration of real samples.

\begin{tabular}{ccc}
\hline Sample & $\begin{array}{c}\text { Potentiometry with novel ISEs } \\
{[\mathrm{mg} / \mathrm{L}]}\end{array}$ & $\begin{array}{c}\text { Ion-chromatography } \\
{[\mathrm{mg} / \mathrm{L}]}\end{array}$ \\
\hline tap water 1 & 24 & 24 \\
tap water 2 & 33 & 30 \\
mineral water & 59 & 55 \\
\hline
\end{tabular}




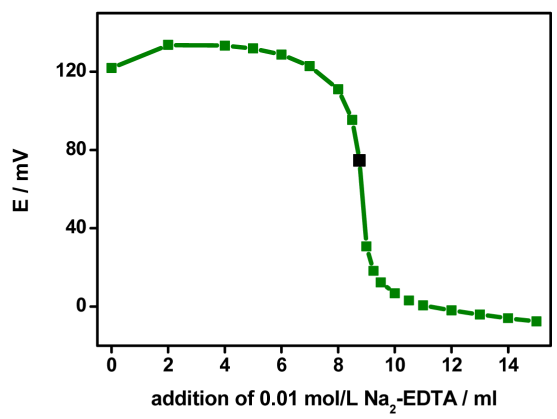

(a)

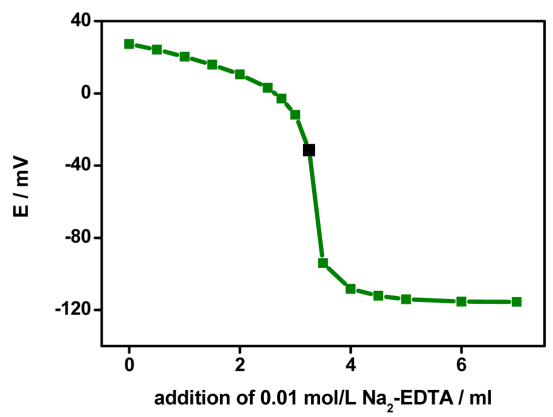

(a)

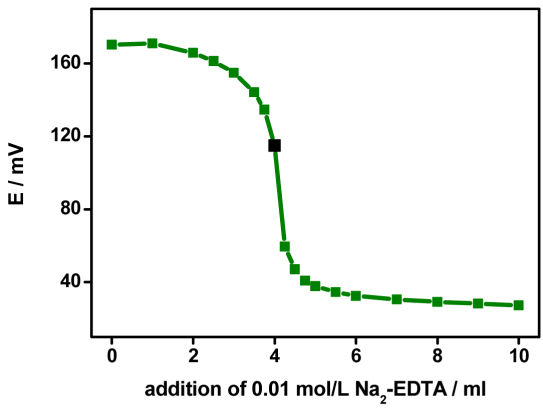

(a)

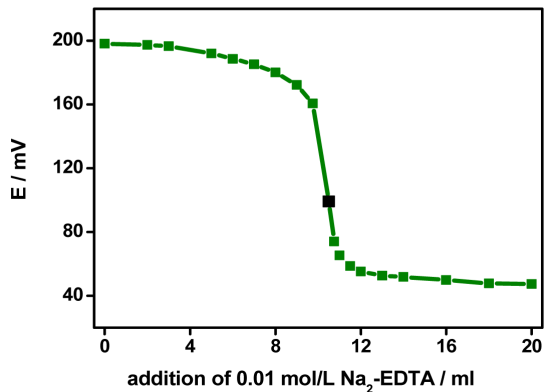

(a)

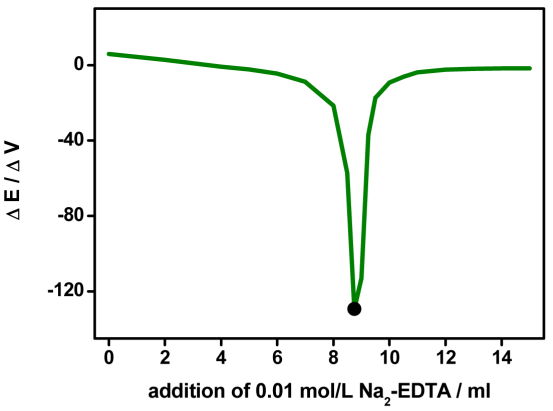

(b)

(A)

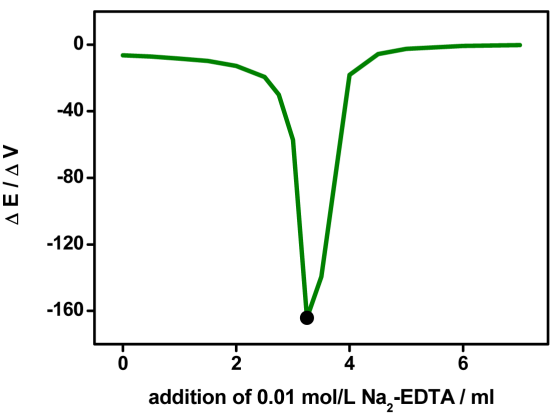

(b)

(B)

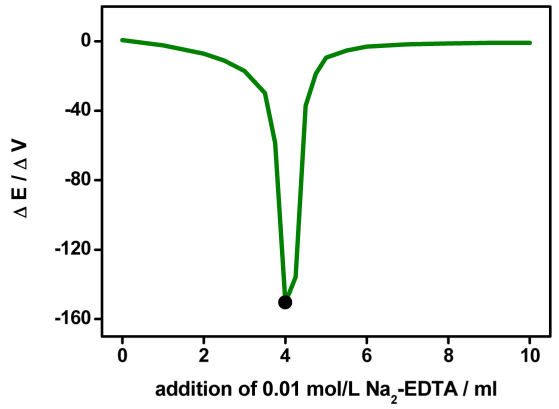

(b)

(C)

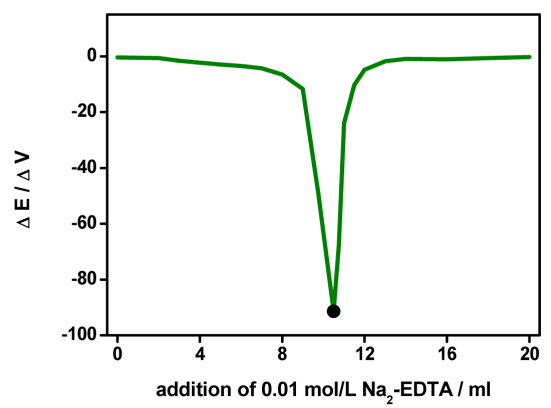

(b)

(D)

Figure 4. Potentiometric titration curves (a) and related first derivatives (b) of different tap water samples, obtained with novel screen-printed $\mathrm{Ca}^{2+}$ selective indicator electrodes: (A) Strasbourg (France); (B) Freiberg (Germany); (C) Garda (Italy); (D) Kolobrzeg (Poland). 
Table 3. $\mathrm{Ca}^{2+}$ determination by titration methods.

\begin{tabular}{cccc}
\hline Tap water samples & $\begin{array}{c}\text { Ion-complexing } \\
\text { compound }\end{array}$ & $\begin{array}{c}\mathrm{Ca}^{2+}[\mathrm{mg} / \mathrm{L}] \text { potentiometric } \\
\text { titration with } A S S \text { sensors }\end{array}$ & $\begin{array}{c}\mathrm{Ca}^{2+}[\mathrm{mg} / \mathrm{L}] \\
\text { colorimetric titration }\end{array}$ \\
\hline $\begin{array}{c}\text { Strasbourg } \\
\text { (France) }\end{array}$ & I & 70 & 72 \\
$\begin{array}{c}\text { Freiberg } \\
\text { (Germany) }\end{array}$ & II & 26 & 28 \\
$\begin{array}{c}\text { Garda } \\
\text { (Italy) }\end{array}$ & I & 32 & 35 \\
$\begin{array}{c}\text { Kolobrzeg } \\
\text { (Poland) }\end{array}$ & II & 84 & 87 \\
\hline
\end{tabular}

different tap water samples are summarized. The obtained $\mathrm{Ca}^{2+}$ contents are in good agreement with results from conventional titration using the color indicator calconcarboxylic acid.

\section{Conclusions}

Screen-printed potentiometric ASS sensors have been used in potentiometric $\mathrm{Ca}^{2+}$ titrations of real samples with EDTA as complexing agent. It has been shown that the described miniaturized, solid-contact sensors can be successfully applied to determine $\mathrm{Ca}^{2+}$ concentrations in environmental samples.

The described solid-contact ISEs, based on diamides as ion-complexing compounds, show stable and reproducible potentials. The sensors excel in robustness, simple construction form and easy handling. ISE and reference electrode, both in ASS configuration, have been positioned in a space-saving way on common miniaturized ceramic substrates. The ISEs are manufactured by screenprinting and have been subsequently modified by applying functional polymeric layers by drop casting. Only a few chemicals are required during sensor production. No glass parts and liquid components were necessary. By using a thin layer of CPs as intermediate layer between the ion-selective PVC membrane and the graphite substrate, reproducible potentials are obtained. Both membrane and intermediate layer show good adhesion and high mechanical stability. Therefore, the $\mathrm{Ca}^{2+}$ determination in water samples can be carried out with high accuracy and precision. The novel low-cost electrochemical sensors exhibited good electrochemical properties and offer great opportunities for applications in mobile environmental ion analysis in future.

\section{Acknowledgements}

The authors thank the Bundesministerium für Bildung und Forschung/Germany for financial support of the project BioNEWS (project number 03WKCL03G). Help in sensor manufacture and conception by Andreas Klockow and Thomas Kretschmar is highly acknowledged. The authors also thank Mrs. Ute Enseleit for carrying out the chromatographic investigations.

\section{References}

[1] Zamani, H.A., Abedini-Torghabeh, J. and Ganjali, M.R. (2006) A Highly Selective 
and Sensitive Calcium(II)-Selective PVC Membrane Based on Dimethyl 1-(4-Nitrobenzoyl)-8-oxo-2,8-dihydro-1H-pyrazolo [5,1-a]isoindole-2,3-dicarboxylate as a Novel Ionophore. Bulletin Korean Chemical Society, 27, 835-840.

https://doi.org/10.5012/bkcs.2006.27.6.835

[2] Vijayalakshmi, A. and Selvi, J.T. (2013) A New Simple Method for the Preparation of Calcium Ion Selective Electrode and Its Analytical Applications. Chemical Science Transactions, 2, 246-250.

[3] Wang, S.-H., Chou, T.-C. and Liu, C.-C. (2003) Development of a Solid-State Thick Film Calcium Ion-Selective Electrode. Sensors and Actuators B, 96, 709-716. https://doi.org/10.1016/S0925-4005(03)00571-9

[4] Shim, J.H., Jeong, I.S., Lee, M.H., Hong, H.P., On, J.H., Kim, K.S., Kim, H.-S., Kim, B.H., Cha, G.S. and Nam, H. (2004) Ion-Selective Electrodes Based on Molecular Tweezer-Type Neutral Carriers. Talanta, 63, 61-71. https://doi.org/10.1016/j.talanta.2003.12.050

[5] Radu, A., Radu, T., McGraw, C., Dillingham, P., Anastasova-Ivanova, S. and Dermond, D. (2013) Ion Selective Electrodes in Environmental Analysis. Journal of the Serbian Chemical Society, 78, 1729-1761. https://dspace.lboro.ac.uk/2134/26762 https://doi.org/10.2298/JSC130829098R

[6] Chumbimuni-Torres, K.Y., Rubinova, N., Radu, A., Kubota, L.T. and Bakker, E. (2006) Solid Contact Potentiometric Sensors for Trace Level Measurements. Analytical Chemistry, 78, 1318-1322. https://doi.org/10.1021/ac050749y

[7] Yu, S., Yuan, Q., Li, F. and Liu, Y. (2012) Improved Potentiometric Response of All-Solid-State $\mathrm{Pb}^{2+}$-Selective Electrode. Talanta, 101, 546-549.

https://doi.org/10.1016/j.talanta.2012.07.100

[8] Schwarz, J., Trommer, K. and Mertig, M. (2016) Novel Screen-Printed All-SolidState Copper(II)-Selective Electrode for Mobile Environmental Analysis. American Journal Analytical Chemistry, 7, 525-532.

[9] Zachara, J.E., Toczylowska, R., Pokrop, R., Zagorska, M., Dybko, A. and Wroblewski, W. (2004) Miniaturised All-Solid-State Potentiometric Ion Sensors Based on PVC-Membranes Containing Conducting Polymers. Sensors and Actuators B, 101, 207-212. https://doi.org/10.1016/j.snb.2004.02.052

[10] Ramanavicius, A., Ramanaviciene, A. and Malinauskas, A. (2006) Electrochemical Sensors Based on Conducting Polymer-Polypyrrole. Electrochimica Acta, 51, 6025-6037. https://doi.org/10.1016/j.electacta.2005.11.052

[11] Hu, J., Stein, A. and Bühlmann, P. (2016) Rational Design of All-Solid State Ion-Selective Electrodes and Reference Electrodes. Trends in Analytical Chemistry, 76, 102-114. https://doi.org/10.1016/j.trac.2015.11.004

[12] Bobacka, J., Ivaska, A. and Lewenstam, A. (2008) Potentiometric Ion Sensors. Chemical Reviews, 108, 329-351.

[13] Bobacka, J. (2006) Conducting Polymer-Based Solid-State Ion-Selective Electrodes. Electroanalysis, 18, 7-18. https://doi.org/10.1002/elan.200503384

[14] Morrin, A., Killard, A.J. and Smyth, M.R. (2003) Electrochemical Characterization of Commercial and Home-Made Screen-Printed Carbon Electrodes. Analytical Letters, 9, 2021-2039. https://doi.org/10.1081/AL-120023627

[15] Kadara, R.O., Jenkinson, N. and Banks, C.E. (2009) Characterization and Fabrication of Disposable Screen Printed Microelectrodes. Electrochemistry Communications, 11, 1377-1380. https://doi.org/10.1016/j.elecom.2009.05.010

[16] Tymecki, L., Glab, S. and Koncki, R. (2006) Miniaturised, Planar Ion-Selective Elec- 
trodes Fabricated by Means of Thick-Film Technology. Sensors, 6, 390-396. https://doi.org/10.3390/s6040390

[17] Jaworska, E., Michalska, A. and Maksymiuk, K. (2017) Polypyrrole NanospheresElectrochemical Properties and Application as a Solid Contact in Ion-Selective Electrodes. Electroanalysis, 29, 123-130. https://doi.org/10.1002/elan.201600554

[18] Rahman, M.A., Kumar, P., Park, D. and Shim, Y. (2008) Electrochemical Sensors Based on Organic Conjugated Polymers. Sensors, 8, 118-141. https://doi.org/10.3390/s8010118

[19] Bobacka, J., Ivaska, A. and Lewenstam, A. (2003) Potentiometric Ion Sensors Based on Conducting Polymers. Electroanalysis, 15, 366-374.

https://doi.org/10.1002/elan.200390042 